\title{
Clinical application of AD-MSCs - A review
}

\author{
Ekaterina Semenova', Magdalena Chroscinska-Krawczyk², Mariusz Piotr Grudniak', \\ Tomasz Oldak', Eugeniusz Krzysztof Machaj' \\ 1 Polish Stem Cell Bank, Warsaw, Poland \\ ${ }^{2}$ Clinic of Paediatric Neurology, III Faculty of Paediatrics, Medical University, Lublin, Poland
}

Semenova E, Chroscinska-Krawczyk M, Grudniak M. P, Oldak T, Machaj E. K. Clinical application of AD-MSCs. A review. J Pre-Clin Clin Res. 2018; 12(3): 100-105. doi: 10.26444/jpccr/94910

\begin{abstract}
Introduction. Mesenchymal stromal/stem cells (MSCs) are a unique type of stem cell which can be successfully used in regenerative medicine. They are safe, have the 'stem cell' ability of self-renewal and under appropriate conditions can differentiate into other types of cells without the problem of teratoma formation. MSCs express the characteristic phenotype

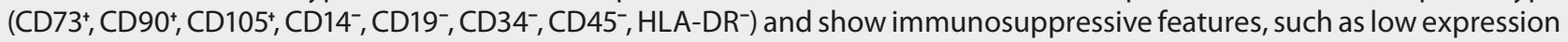
of $\mathrm{MHC} \mathrm{I}$, lack of $\mathrm{MHC} \mathrm{II} \mathrm{and} \mathrm{secretion} \mathrm{of} \mathrm{a} \mathrm{wide} \mathrm{variety} \mathrm{of} \mathrm{immunoprotective} \mathrm{cytokines} \mathrm{and} \mathrm{growth} \mathrm{factors.} \mathrm{One} \mathrm{of} \mathrm{the} \mathrm{MSC}$ sources is adipose tissue, which has some advantages compared with other existing sources. Currently, adipose tissue as a source of mesenchymal stromal/stem cells have become of interest due to a less invasive procedure of isolation and safety. This review contains data from various studies about the usage of adipose-derived MSCs in the treatment of different diseases.

Objectives. The main aim of this review is evaluation of the useful characteristics of adipose-derived mesenchymal stem cells and their usage in stem cell treatment of some diseases. The aim is to describe the current knowledge and future perspectives.

Conclusions. Adipose-derived MSCs (AD-MSCs) represent a good tool in regenerative stem cell therapy.
\end{abstract}

\section{Key words}

adipose-derived mesenchymal stem cell (AD-MSC), stem cell therapy, regenerative medicine

\section{INTRODUCTION}

Mesenchymal Stem/Stromal Cells (MSCs) are widely used in the field of regenerative medicine, but their optimal source is still being sought. Friedestein was the first to isolate and identify MSCs from bone marrow [1]. Later, MSCs were successfully isolated from a range of tissues and organs: adipose tissue, peripheral blood, amniotic fluid, placenta and umbilical cord [2,3]. The bone marrow-derived MSCs are commonly used in clinics for many applications, including to stimulate growth in patients with osteogenesis imperfecta, repair of articular cartilage defects and prevent death from GVHD (Graft-versus-host disease) [4, 5, 6]. Another source of MSCs is adipose tissue. Isolation from this tissue has some important advantages compared to bone marrow: it is safer for the donor and less time consuming. The most widely used procedure to obtain adipose tissue is liposuction. According to the American Society for Aesthetic Plastic Surgery, liposuction was included in the top five surgical procedures in 2016 (Statistic Cosmetic Surgery National Data Bank Statistics 2016). Generally, liposuction is safe for the patient, less invasive and well tolerated. The cells can be isolated using special automated devices, e.g. SmartLipo ${ }^{\text {tm }}$ (Cynosure Inc., Westford, MA, USA), MicroAire Surgical Instruments (Charlottesville, VA, USA) or protocol of manual isolation (Fig. 1) [7].

After liposuction, two cell populations are available:

- Stromal Vascular Fraction (SVF).

- Adipose-Derived Mesenchymal Stem/Stromal Cells (ADMSCs).

Address for correspondence: Ekaterina Semenova, Polish Stem Cell Bank, Działkowa 85, 02-234 Warsaw, Poland

E-mail: Ekaterina.Semenova@pbkm.pl

Received: 19.06.2018; Accepted: 05.09.2018

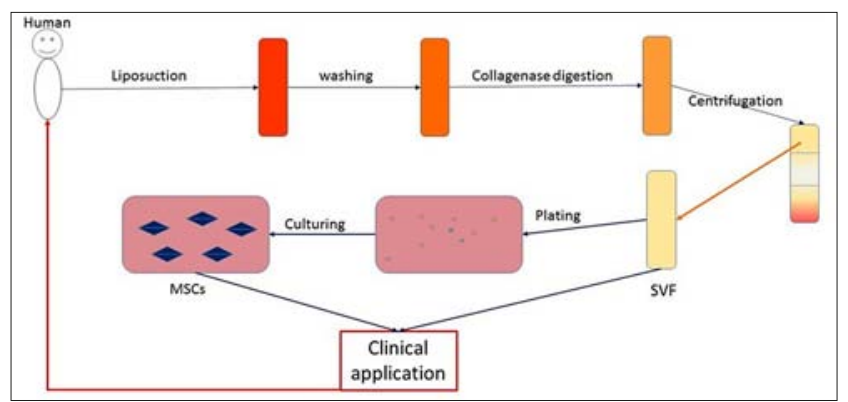

Figure 1. Scheme of SVF and adipose-derived MSCS (AD-MSCs) isolation procedure SVF and AD-MSCs are extracted from adipose tissue in a multistep procedure

SVF is a heterogeneous cell population which includes some blood cells (erythrocytes, monocytes), fibroblasts, smooth muscle cells, EPC (endothelial progenitor cells), pericytes and MSCs (Fig. 2) [8]. Therefore, SVF is characterized by

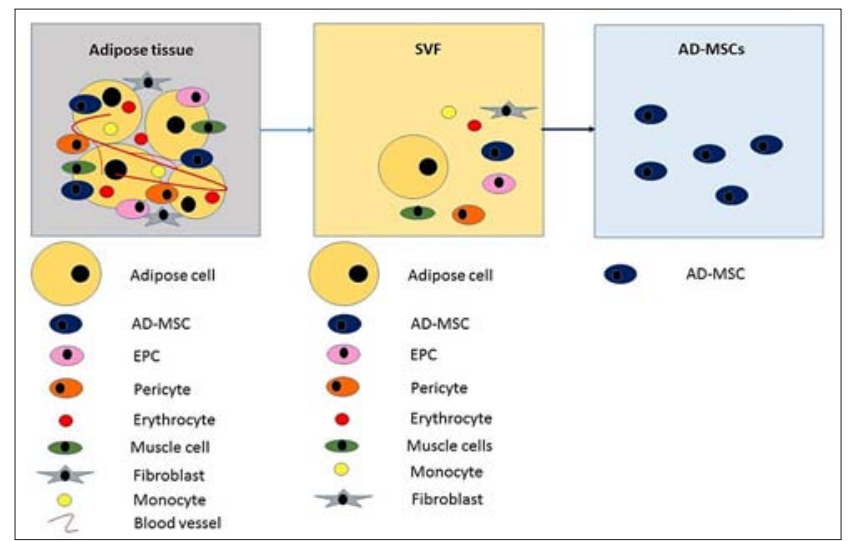

Figure 2. Differences between SVF and a MSC fraction. SVF is a mixture of various cells. AD-MSCs are a pure population of cells derived from SVF after culturing. EPC - epithelial progenitor cell 
the presence of $\mathrm{CD} 34^{+}, \mathrm{CD} 45^{+}, \mathrm{CD}_{3}+\mathrm{CD}^{+} 0^{+}, \mathrm{CD} 105^{+}$and other CD cell surface markers $[9,10]$. SVF is rich in many growth factors: IGF-1 (Insulin-like growth factor 1), VEGF (Vascular endothelial growth factor), PDGF (Platelet-derived growth factor) and FGF (Fibroblast growth factor) [11]. In clinical aplication in which fast angiogenesis is important, SVF is used successfully $[12,13]$.

To isolate AD-MSCs, SVF is cultured under special conditions. AD-MSCs have a standard fibroblast-like form, are characterized by the presence of $\mathrm{CD}^{2} 3^{+}, \mathrm{CD} 90^{+}, \mathrm{CD} 105^{+}$ and $\mathrm{CD} 34^{-}, \mathrm{CD}_{4} 5^{-}, \mathrm{HLA}-\mathrm{DR}^{-}$cells, and have the possibility to differentiate osteogenic, adipogenic and chondrogenic lineages (Fig. 3), which fulfills the minimal criteria of MSC established by the International Society of Cellular Therapy $[9,10,14]$.

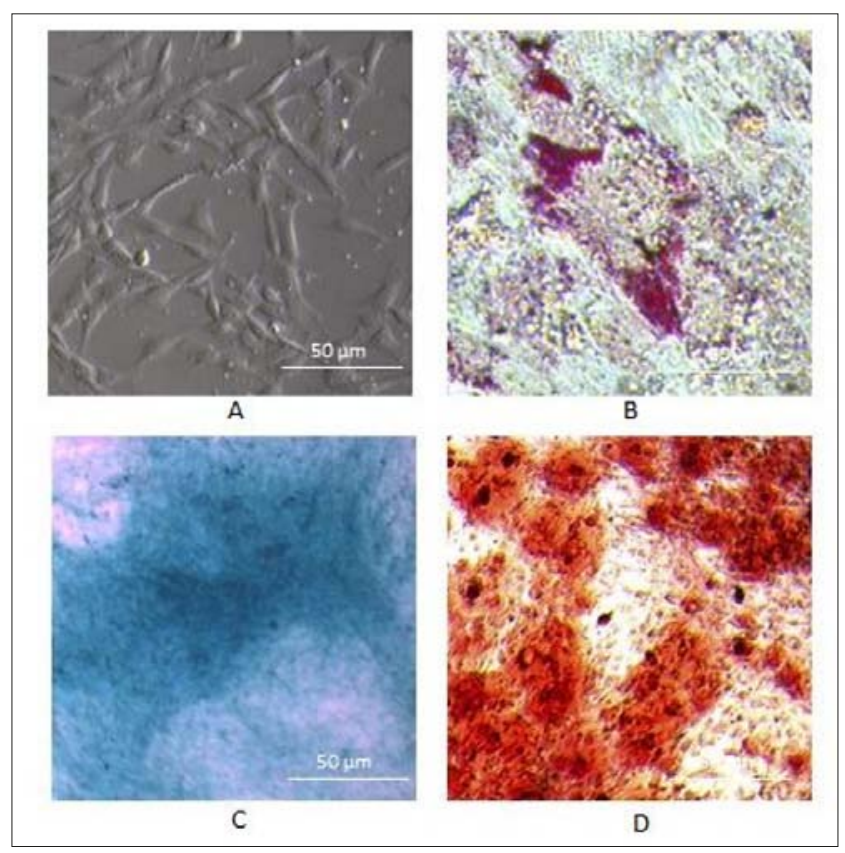

Figure 3. AD-MSCs in culture. A - undifferentiated cells; B - adipocytes; C chondrocytes; D - osteoblasts

AD-MSCs have the ability (similar to SVF) to secrete various important factors, such as TNF- $\alpha$ (Tumour Necrosis Factor-alpha), TGF- $\beta$ (transforming growth factor-beta), VEGF, HGF (Hepatocyte Growth Factor), and some interleukins. In 2004, Rehman et al. reported that AD-MSCs, under hypoxia condition, secrete a considerable amount of VEGF and HGF and induce healing in mice hindlimb ischemia [15]. The cytokines which AD-MSCs expressed affect the differentiation of these cells. VEGF and HGF increase the chondrogenic and hepatogenic differentiation of AD-MSCs in vitro, respectively [16, 17]. FGF promotes and increases adipogenic and chondrogenic differentiation in vitro, but blocks osteogenic differentiation, whereas EGF inhibits adipogenic differentiation [18].

According to Salgado et al., AD-MSCs demonstrated an immunomodulatory ability, which was closely connected with their secretome [19] (Fig. 4). Besides the immunomodulatory properties of MSCs, Spaeth et al. showed their capacity to migrate to sites of injury or inflammation [20].

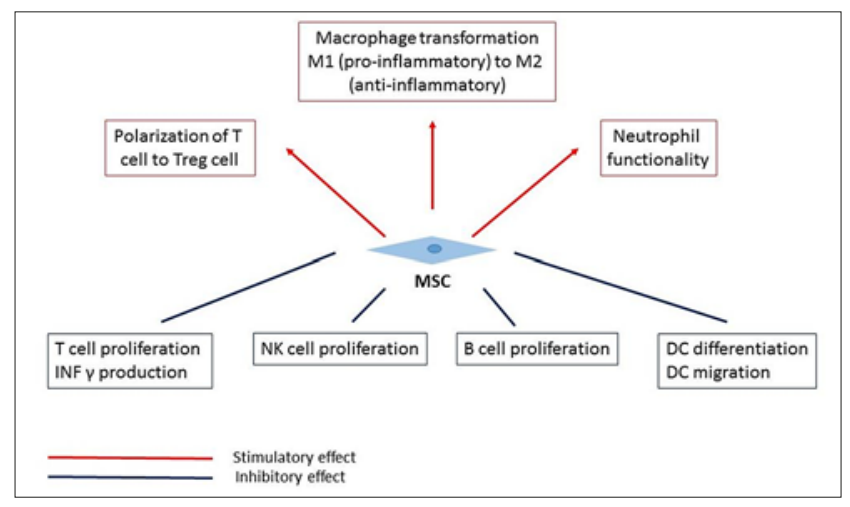

Figure 4. Scheme of MSCs immunomodulation activity. MSCs inhibit proliferation and maturation of immune cells. They suppress immune reaction in vitro and in vivo

\section{USAGE OF AD-MSCS}

Wound healing. Skin is a tissue with natural possibilities of self-repair after injury. Correct healing leads to repairing skin integrity and consists of a few stages: activation of cells (immune cells, fibroblasts, MSCs), proliferation of cells and skin remodeling (re-epithelialization). Methods of wound treatment include hyperbaric $\mathrm{O}_{2}$ [21], various growth factors (FGF, EGF (epidermal growth factor), TGF- $\beta$, VEGF, SDF-1 (stromal cell-derived factor 1) $[22,23]$ and stem cell treatment.

Stem cell treatment appears to be most promising (Tab. 1). AD-MSCs are good candidates for wound treatment because they secrete many cytokines and growth factors which improve wound healing [24] and vascularization [25]. The Huang research group used the fourth passage with a high level of secretory protein expression (VEGF, HGF) [26]. They demonstrated immediate effects of AD-MSCs and/or paracrine activity in rat model in vivo. These effects were shown earlier

Table 1. Properties of AD-MSCs useful for regenerative medicine

\begin{tabular}{|c|c|c|c|}
\hline Property & Study & Mechanism & Reference \\
\hline \multirow[t]{3}{*}{$\begin{array}{l}\text { Paracrine } \\
\text { activity }\end{array}$} & $\begin{array}{l}\text { hAD-MSCs produce } \\
\text { VEGF, HGF, and IGF-I }\end{array}$ & $\begin{array}{l}\text { Production of cytokines and } \\
\text { growth factors in response } \\
\text { to TNF by a p38 MAPK- } \\
\text { dependent mechanism }\end{array}$ & $\begin{array}{l}\text { Wang et al., } \\
2006\end{array}$ \\
\hline & $\begin{array}{l}\text { hAD-MSCs secrete } \\
\text { angiogenic and } \\
\text { antiapoptotic growth } \\
\text { factors }\end{array}$ & $\begin{array}{l}\text { The enhancement of } \\
\text { protein expression by } \\
\text { hypoxia }\end{array}$ & $\begin{array}{l}\text { Rehman } \\
\text { et al., } 2004\end{array}$ \\
\hline & $\begin{array}{l}\text { hAD-MSCs produce } \\
\text { some neuroprotective } \\
\text { factors, e.g. FGF, IGF, } \\
\text { BDNF (brain-derived } \\
\text { neurotrophic factor) }\end{array}$ & $\begin{array}{l}\text { Co-cultivation of AD-MSCs } \\
\text { with Schwann cells to } \\
\text { increase the efficiency to } \\
\text { produce neuroprotective } \\
\text { factors and to improve } \\
\text { neural differentiation }\end{array}$ & $\begin{array}{l}\text { Liao et al., } \\
\text { 2010; } \\
\text { Lopatina } \\
\text { et al., 2011; } \\
\text { Marconi } \\
\text { et al., } 2012\end{array}$ \\
\hline \multirow[t]{2}{*}{$\begin{array}{l}\text { Enhance } \\
\text { angiogenesis }\end{array}$} & $\begin{array}{l}\text { hSVF transplantation } \\
\text { to mouse hind limb }\end{array}$ & $\begin{array}{l}\text { Differentiation of } \\
\text { endothelial cells }\end{array}$ & $\begin{array}{l}\text { Nakagami } \\
\text { et al., } 2005\end{array}$ \\
\hline & $\begin{array}{l}\text { rAD-MSCs in radiation } \\
\text { ulcer of a rat model }\end{array}$ & $\begin{array}{l}\text { Production of cytokines } \\
\text { (SDF-1, VEGF, HGF) }\end{array}$ & $\begin{array}{l}\text { Huang } \\
\text { et al., } 2013\end{array}$ \\
\hline \multirow[t]{2}{*}{$\begin{array}{l}\text { Wound } \\
\text { healing } \\
\text { promotion }\end{array}$} & $\begin{array}{l}\text { rAD-MSCs in radiation } \\
\text { ulcer of a rat model }\end{array}$ & $\begin{array}{l}\text { Production of cytokines } \\
\text { (VEGF, HGF) promote } \\
\text { angiogenesis (new blood } \\
\text { vessel formation) }\end{array}$ & $\begin{array}{l}\text { Huang } \\
\text { et al., } 2013\end{array}$ \\
\hline & $\begin{array}{l}\text { Skin wound in rat } \\
\text { model }\end{array}$ & $\begin{array}{l}\text { Production of cytokines } \\
\text { (VEGF, HGF) improve } \\
\text { the cell proliferation and } \\
\text { neovascularization }\end{array}$ & $\begin{array}{l}\text { Sheng } \\
\text { et al., } 2013\end{array}$ \\
\hline
\end{tabular}


by the Rehman group in mouse ischemia model in vivo [15]. Huang et al. also have shown that transplantation of AD-MSCs after culturing intensifies the process of wound healing due to the increase of blood supply and granulation rate. Huang also demonstrated that AD-MSCs were present in the injury area for 14 days, which suggests their long-term activity.

The use of auxiliary natural/synthetic components, such as fibroin-chitozan scaffold, collagen scaffold, cellular matrix scaffold, biopolymeric scaffold for local AD-MSCs treatment, probably improves the healing of wounds due to scaffoldmediated inductive processes (e.g. generation of bioactive peptides) $[27,28]$.

Kuo et al. reported that AD-MSCs can improve diabetic wound healing in an streptozotocin-induced animal model of diabetes [29]. Rats were treated subcutaneously in the diabetic inflammatory region with AD-MSCs (nondiabetic). In comparison with the control group, the group treated by AD-MSCs showed a reduced area of wound and improved angiogenesis.

At least three clinical studies with key words 'wound heal' and 'AD-MSC' were registered on clinicaltrials.gov (database as of 02.02.2018).

Regeneration of nerves. Injuries to peripheral nerves result in chronic pain and lead to disability in many patients. Using electrical stimuli, magnetic field and drugs increase nerve regeneration, and thanks to the progress in surgery in recent years recovery is improved. A promising option to regenerate nerves is stem cell-based therapy. Marconi et al. confirmed that AD-MSCs intravenous administration one week after sciatic nerve crush injury in a murine model of acute axonal damage, significantly increased functional recovery. Besides the decrease of inflammation, the authors suggested that AD-MSCs could produce some neuroprotective factors, e.g. FGF, IGF in mouse model of sciatic crush [30]. Another scientific group confirmed in a mice in vitro study that ADMSCs express multiple genes necessary for the nerve growth and myelination [31]. The BDNF production by AD-MSCs stimulated nerve repair and growth.

Currently, studies based on the use of mesenchymal stem cells from different tissues, including MSCs from adipose tissue, are widely used. The easy access and possibility of autologous cell source make MSCs from adipose tissue more accessible than MSCs from any other sources. Intravenous administration of MSCs improves regeneration of the axons $[32,33]$. The expression of special genes (peripheral myelin protein 22 , myelin basic protein) by AD-MSCs is required for nerve repair and improves myelination.

Another method is the use of co-cultivation of ADMSCs with Schwann cells to increase the efficiency of axon regeneration and improves neural differentiation [34, 35]. Schwann cells are the key player in nerve regeneration, but use of these cells is limited because of invasive procedure of isolation. AD-MSCs demonstrate successfully the differentiation into neuronal lineage and Schwan cells [36]. In addition, AD-MSCs can produce some neurotrophic factors, such as NGF (nerve growth factor) and BDNF [15, 30, 31]. The co-culture AD-MSCs with Schwan cells stimulates the AD-MSCs to differentiate into Schwann cells [37].

The method using AD-MSCs with growth factor TGF- $\beta$ demonstrates that AD-MSCs are protected from apoptosis due to inflammation inhibition and enhancement of angiogenesis in vivo [38].
At least one clinical study with key words 'nerve injury' and 'AD-MSC' were registered on clinicaltrials.gov (database as of 02.02.2018).

Soft tissue reconstruction/craniofacial surgery. In reconstructive surgery, SVF and AD-MSCs are an important source due to their ability to stimulate angiogenesis, immunomodulation and multi-differentiation. Clinical therapies use the ability of AD-MSCs to differentiate chondrocytes, osteocytes and adipocytes for reconstructive surgery to repair cartilage, bone or soft tissue defects. The natural ability of AD-MSCs to differentiate chondrocytes is supported by a mixture of special ingredients and growth factors: TGF $\beta$, dexamethasone and ascorbate. Some scientific groups which have used special culturing techniques and biomaterials (3D micromass culture, porous hyaluronic acid scaffold, fibrin glue scaffold, alginate microbeads, adding TGF- $\beta$ ) demonstrated improvement in the effectiveness of chondrogenic differentiation in vivo [39-44].

AD-MSCs were first used in 2004 in bone reconstruction [45]. AD-MSCs, in cooperation with autologous bone and fibrin glue, can stimulate new bone formation [46]. Using granules ( $\beta$-tricalcium phosphate) and scaffolds helps bone repair $[47,48]$.

AD-MSCs have a high potential to differentiate into adipocytes and to promote angiogenesis [49]. Adding ADMSCs to fat graft can increase the survival of transplanted cells [50]. Using a combination of an SVF population and adipose tissue produced better results in terms of transplant survival than using cells without SVF, as performed in 9 patients [51].

At least three clinical studies with key words «soft tissue defect〉, 〈bone defec)" and 〈AD-MSC〉 were registered on clinicaltrials.gov (database as of 02.02.2018).

Diseases affecting skin. Acne is a stressful, long-term skin disease. As described previously, AD-MSCs increase wound healing. Zhou et al. showed the effectiveness of conditioned media of MSCs derived from adipose tissue in the treatment of 13 patients with atrophic acne scars [52]. They observed increased hydration and skin elasticity, higher concentration of dermal collagen and higher elastin density. Due to their possibility to produce various growth factors, such as bFGF, KGF (keratinocyte growth factor), TGF- $\beta 1$, HGF, VEGF, conditioned medium of AD-MSCs increases the production of dermal collagen and fibroblasts migration into the dermis, which can be used to decrease/eliminate wrinkles and even improve facial defects.

Injection of AD-MSCs to a dermal substitute improves human skin regeneration by increasing angiogenesis and collagen production [53]. In 2013, Salahat and Hadid noticed that using AD-MSCs in vivo caused the growth of human vascular endothelial cells, which promoted wound healing, generation of new blood vessels, and increased production of collagen and hyaluronic acid due to the synthesis of various growth factors described previously [54]. These two substances (collagen and hyaluronic acid) are also used in beauty injection therapy to treat some skin defects. Using AD-MSCs in combination with platelet-rich plasma (PRP) in atrophic scars treatment brought good results in human, such as the healing of acne pustules and elimination of hyperpigmentation [55]. After the second session of treatment, the acne scars were less visible. PRP rich in growth factors, 
such as PDGF, VEGF, TGF- $\beta$, EGF, FGF, IGF-1, are required for skin regeneration and promotion of angiogenesis.

Treatment of obesity. The rate of obesity cases have risen dramatically in recent years. This is connected with a higher risk of metabolic diseases, such as diabetes, hyperlipidaemia or cardiovascular diseases. As a potential treatment, adiposederived cell therapy has been suggested. Studies are underway to understand the role of adipose tissue and adipose stem cells in obesity and to find potential therapy targets.

Obesity causes an excess of chronic energy and lipid storage in white adipose tissue [56]. This results in an imbalance between two processes: lipogeneses and lipolysis. In vitro in hypoxic conditions, adipocytes secrete various inflammatory cytokines, e.g. TNFa, Il1, IL6, and others [57]. These cytokines affect necrotic cells to eliminate them and cause tissue inflammation. Moreover, obese AD-MSCs are defective in important functions, such as differentiation, immunomodulation, self-renewal capabilities and promotion of angiogenesis [58]. Additionally, adipose cells begin to possess insulin resistance and lead to different metabolic diseases.

Cao described angiogenesis as a therapeutic target for obesity and metabolic diseases $[59,60]$. Angiogenesis is crucial for the whole organism processes of the formation of new blood vessels. Adipose tissue is one of the most vascularized tissue in the organism, and the development of adipose tissue depends on the continuous remodeling and development of vascularization [61]. High vascularization in brown adipose tissue increases metabolism by providing oxygen molecules. Supported by earlier studies, the identification of AD-MSCs as a part of the vasculature niche claims that adipocytes develop in close contact with blood vessels [62]. Under hypoxic conditions, expression of angiogenic factors in adipose tissue was changed by increasing the level of VEGF and leptin [63]. VEGF and IGF are angiogenic factors, and the lack of these factors may lead to endothelial cell apoptosis. One of the possible strategies may be the blockade of the function of these factors, which may lead to the regress of adipose vessels and fat reduction. Another promising way of obesity treatment is gene therapy. The use of nonviral nucleic acid transfer into human AD-MSCs as a new method of stem cell treatment, demonstrates the potential of therapy with modificated stem cells [64].

It is crucial to find potential therapy targets in obesity disease, because defective AD-MSCs play an important role in the development of obesity diseases: insulin resistance, inflammation and metabolic disorders.

At least oneinical study with key ords 'besity' and 'D-MSC'were registered on clinicaltrials.gov (database as of 10.02.2018).

Concluding remarks. With their unique possibilities, such as high proliferation potential, ability to secrete several growth factors and to differentiate at least into three cell lines, the use of AD-MSCs can significantly improve and increase the quality of regenerative processes or damaged tissue reconstruction.

The attractiveness of using these is also enhanced by the way of their isolation. The availability, safety and simplicity of isolation of AD-MSCs make it the preferred resource for preclinical and clinical studies. The adipose tissue as a primary material is collected by the classic method of liposuction, and the protocol for cell isolation is known. The procedure of liposuction has been improved over the years, making this process the most popular aesthetic procedure in the world. Another important fact is that AD-MSCs are autologous cells. Patients can use their own cells in a range of surgical procedures without any complication. Autologous cells from adipose tissue are recognized as an ideal filler for the soft tissue replenishment due to their properties, like biocompatibility, readily availability, among others.

It is also important to remember the fact that SVF is a mixture of different cells, not only stem cells. Multiple recent studies show that AD-MSCs secrete several factors that affect different cell populations, and it is probable that there are some factors, expressed by AD-MSCs which may influence on target cells, but are not detected by current techniques. The better understanding of these unknown factors changes and expands the standard approach to AD-MSCs application. Furthermore, the mechanism of AD-MSCs action is still debatable. Presumably, the clinical effect of AD-MSCs is a synergetic, more composite, and consists of the combination of differentiation and secreting ability.

To-date, more than 100 clinical studies using AD-MSCs have been registered. However, the difficulties with access to the results and the lack of systematic reporting of outcomes renders these therapies controversial and need much more evaluation.

\section{Acknowledgements}

This study was supported by Grant STRATEGMED2/267976/13/NCBR/2015 from the National Centre for Research and Development. The authors acknowledge the assistance of Magdalena Sendek, Mardin Mobasheri and Anna Rożycka in reviewing the study.

\section{Abbreviations}

MSCs - Mesenchymal stromal/stem cells

MHC - Major histocompatibility complex

AD-MSCs - Adipose-derived mesenchymal stromal/stem cells

GVHD - Graft-versus-host disease

SVF - Stromal Vascular Fraction

EPC - Epithelial precursor cell

IGF-1 - Insulin-like growth factor 1

VEGF - Vascular endothelial growth factor

PDGF - Platelet-derived growth factor

FGF - Fibroblast growth factor

TNF- $\alpha$ - Tumor Necrosis Factor-alpha

TGF- $\beta$ - transforming growth factor-beta

HGF - Hepatocyte Growth Factor

EGF - Epidermal growth factor

SDF-1 - Stromal cell-derived factor 1

BDNF - brain-derived neurotrophic factor

NGF - Nerve growth factor

KGF - Keratinocyte growth factor

IL - Interleukin

PRP - Platelet-rich plasma

\section{REFERENCES}

1. Friedenstein AJ, Gorskaja JF, Kulagina NN. Fibroblast precursors in normal and irradiated mouse hematopoietic organs. Exp Hematol. 1976; 4: 267.

2. Kmiecik G, Niklinska W, Kuc P, Pancewicz-Wojtkiewicz J, Fil D, et al. Fetal membranes as a source of stem cells. Adv Med Sci. 58: 185-95. 
3. Marcus AJ, Woodbury D. Fetal stem cells from extra-embryonic tissues: Do not discard. J Cell Mol Med. 2008; 12: 730-42.

4. Horwitz EM, Gordon PL, Koo WK, et al. Isolated allogeneic bone marrow-derived mesenchymal cells engraft and stimulate growth in children with osteogenesis imperfecta: implications for cell therapy of bone. Proc Natl Acad Sci USA. 2002; 99: 8932-8937.

5. Wakitani S, Nawata M, Tensho K, et al. Repair of articular cartilage defects in the patello-femoral joint with autologous bone marrow mesenchymal cell transplantation: three case reports involving nine defects in five knees. J Tissue Eng Regen Med. 2007; 1: 74-79.

6.Baron F, Lechanteur C, Willems E, et al. Cotransplantation of mesenchymal stem cells might prevent death from graft-versushost disease (GVHD) without abrogating graft-versus-tumor effects after HLA-mismatched allogeneic transplantation following nonmyeloablative conditioning. Biol Blood Marrow Transplant. 2010; 16: 838-847.

7.Shridharani SM, Broyles JM, Matarasso A. Liposuction devices: technology update. Med Devices (Auckl). 2014; 7: 241-251.

8. Cawthorn WP, Scheller EL, MacDougald OA. Adipose tissue stem cells meet preadipocyte commitment: going back to the future. J Lipid Res. 2012; 53(2): 227-46.

9. Mitchell JB, McIntosh K, Zvonic S, et al. Immunophenotype of human adipose-derived cells: temporal changes in stromal-associated and stem cell-associated markers. Stem Cells. 2006; 24: 376-385.

10. Brzoska M, Geiger H, Gauer S, Baer P. Epithelial differentiation of human adipose tissue-derived adult stem cells. Biochem Biophys Res Commun. 2005; 330(1): 142-50.

11. Grasys J, Kim BS, Pallua N. Content of Soluble Factors and Characteristics of Stromal Vascular Fraction Cells in Lipoaspirates from Different Subcutaneous Adipose Tissue Depots. Aesthet Surg J. 2016; 36: 831-841.

12. Yoshimura K, Asano Y, Aoi N, et al. Progenitor-enriched adipose tissue transplantation as rescue for breast implant complications. Breast J. 2010; 16(2): 169-75.

13. Yoshimura K, Sato K, Aoi N, Kurita M, Hirohi T, Harii K. Cell-Assisted Lipotransfer for Cosmetic Breast Augmentation: Supportive Use of Adipose-Derived Stem/Stromal Cells. Aesthetic Plast Surg. 2008; 32(1): 48-55.

14. Dominici M, Le Blanc K, Mueller I, et al. Minimal criteria for defining multipotent mesenchymal stromal cells. The International Society for Cellular Therapy position statement. Cytotherapy. 2006; 8: 315-317.

15. Rehman J, Traktuev D, Li J, et al. Secretion of angiogenic and antiapoptotic factors by human adipose stromal cells. Circulation. 2004; 109: 1292-8.

16. Song SY, Chung HM, Sung JH. The pivotal role of VEGF in adiposederived-stem-cell-mediated regeneration. Expert Opin Biol Ther. 2010; 10: 1529-1537.

17. Seo MJ, Suh SY, Bae YC, Jung JS. Differentiation of human adipose stromal cells into hepatic lineage in vitro and in vivo. Biochem Biophys Res Commun. 2005; 328: 258-264.

18. Tsuji W, Rubin JP, Marra KG. Adipose-derived stem cells: Implications in tissue regeneration. World J Stem Cells. 2014; 26; 6(3): 312-321.

19. Salgado AJ, Reis RL, Sousa NJ, Gimble JM. Adipose tissue derived stem cells secretome: soluble factors and their roles in regenerative medicine. Curr Stem Cell Res Ther. 2010; 5(2): 103-10.

20.Spaeth E, Klopp A, Dembinski J, Andreeff M, Marini F. Inflammation and tumor microenvironments: defining the migratory itinerary of mesenchymal stem cells. Gene Ther. 2008; 15(10): 730-8.

21. Bhutani S, Vishwanath G. Hyperbaric oxygen and wound healing. Indian J. Plast Surg. 2012; 45(2): 316-324.

22. Han G, Ceilley R. Chronic Wound Healing: A Review of Current Management and Treatments. Adv. Ther. 2017; 34(3): 599-610.

23. Kato T, Khanh VC, Sato K, Takeuchi K, et al. SDF-1 improves wound healing ability of glucocorticoid-treated adipose tissue-derived mesenchymal stem cells. Biochem Biophys Res Commun. 2017; 493(2): $1010-1017$.

24. Wang M, Crisostomo PR, Herring C, et al. Human progenitor cells from bone marrow or adipose tissue produce VEGF, HGF, and IGF-I in response to TNF by a 38 MAPK dependent mechanism. Am J Physiol Regul Integr Comp Physiol. 2006; 291: R880-4.

25. Ebrahimian TG, Pouzoulet F, Squiban C, et al. Cell therapy based on adipose tissue derived stromal cells promotes physiological and pathological wound healing. Arterioscler Thromb Vasc Biol. 2009; 29: 503-10.

26. Huang SP, Huang CH, Shyu JF, et al. Promotion of wound healing using adipose-derived stem cells in radiation ulcer of a rat model. Journal of Biomedical Science. 2013; 20(1): 51.
27. Turner NJ, Badylak SF. The Use of Biologic Scaffolds in the Treatment of Chronic Nonhealing Wounds. Adv Wound Care (New Rochelle). 2015; 4(8): 490-500.

28. Dickinson LE, Gerecht S. Engineered Biopolymeric Scaffolds for Chronic Wound Healing Front Physiol. 2016; 5(7): 341.

29. Kuo YR, Wang CT, Cheng JT, et al. Adipose-derived stem cells accelerate diabetic wound healing through the induction of autocrine and paracrine effects. Cell Transplant. 2016; 25: 71-81.

30. Marconi S, Castiglione G, Turano E, et al. Human Adipose-Derived Mesenchymal Stem Cells Systemically Injected Promote Peripheral Nerve Regeneration in the Mouse Model of Sciatic Crush. Tissue Engineering. 2012; 18: 11-12.

31.Lopatina T, Kalinina N, Karagyaur M, et al. Adipose-derived stem cells stimulate regeneration of peripheral nerves: BDNF secreted by these cells promotes nerve healing and axon growth de novo. PLoS One. 2011; 6: el7899.

32. Matthes SM, Reimers K, Janssen I, et al. Intravenous transplantation of mesenchymal stromal cells to enhance peripheral nerve regeneration. Biomed Res Int. 2013; 2013: 573169.

33. Fairbairn NG, Meppelink AM, Ng-Glazier J, Randolph MA, Winograd JM. Augmenting peripheral nerve regeneration using stem cells: A review of current opinion. World J Stem Cells. 2015; 7: 11-26.

34. Liao T, Moussallem MD, Kim J, Schlenoff JB, Ma T. N-isopropylacrylamide-based thermoresponsive polyelectrolyte multilayer films for human mesenchymal stem cell expansion. Biotechnol Prog. 2010; 26(6): 1705-13.

35. Dai LG, Huang GS, Hsu SH. Sciatic nerve regeneration by cocultured Schwann cells and stem cells on microporous nerve conduits. Cell Transplant. 2013; 22(11): 2029-39.

36. Kingham PJ, Kalbermatten DF, Mahay D, Armstrong SJ, Wiberg M, Terenghi G. Adipose-derived stem cells differentiate into a Schwann cell phenotype and promote neurite outgrowth in vitro. Exp. Neurol. 2007; 207(2): 267-274.

37. Wei Y, Gong K, Zheng Z, et al. Schwann-like cell differentiation of rat adipose-derived stem cells by indirect coculture with Schwann cells in vitro. Cell Prolif. 2010; 43(6): 606-616.

38. Luo H, Zhang Y, Zhang Z, Jin Y. The protection of MSCs from apoptosis in nerve regeneration by TGF $\beta 1$ through reducing inflammation and promoting VEGF-dependent angiogenesis. Biomaterials. 2012; 33(17): 4277-87.

39. Denker AE, Nicoll SB, Tuan RS. Formation of cartilage-like spheroids by micromass cultures of murine $\mathrm{C} 3 \mathrm{H} 10 \mathrm{~T} 1 / 2$ cells upon treatment with transforming growth factor-beta 1. Differentiation. 1995; 59: 25-34.

40. Yoon IS, Chung CW, Sung JH, et al. Proliferation and chondrogenic differentiation of human adipose-derived mesenchymal stem cells in porous hyaluronic acid scaffold. Journal of Bioscience and Bioengineering 2011; 112: 402-408.

41.Dragoo JL, Carlson G, McCormick F, et al. Healing full-thickness cartilage defects using adipose-derived stem cells. Tissue Engineering. 2007; 13: 1615-1621.

42. Leslie SK, Cohen DJ, Sedlaczek J, et al. Controlled release of rat adiposederived stem cells from alginate microbeads. Biomaterials. 2013; 34 : 8172-8184.

43. Lin Y, Luo E, Chen X, et al. Molecular and cellular characterization during chondrogenic differentiation of adipose tissue-derived stromal cells in vitro and cartilage formation in vivo. Journal of Cellular and Molecular Medicine. 2005; 9: 929-939.

44. Estes BT, Wu AW, Guilak F. Potent induction of chondrocytic differentiation of human adipose-derived adult stem cells by bone morphogenetic protein 6 . Arthritis and Rheumatism. 2006; 54: 12221232.

45. Hoekstra A. Prospering on the Fat of the Land: Adipose-derived stem cells as an industrially-viable resource for regenerative treatment. MMG 445 Basic Biotechnology. 2011; 7: 24-30.

46. Lendeckel S, Jodicke A, Christophis P, et al. Autologous stem cells (adipose) and fibrin glue used to treat widespread traumatic calvarial defects: case report. J Cranio-Maxillo-Facial Surg. 2004; 32: 370-3.

47. Thesleff T, Lehtimaki K, Niskakangas T, et al. Cranioplasty with adipose-derived stem cells and biomaterial: a novel method for cranial reconstruction. Neurosurgery. 2011; 68: 1535-40.

48. Sandor GK, Tuovinen VJ, Wolff J, et al. Adipose stem cell tissueengineered construct used to treat large anterior mandibular defect: a case report and review of the clinical application of good manufacturing practice-level adipose stem cells for bone regeneration. J Oral Maxillofac Surg. 2013; 71: 938-50.

49. Yoshimura K, Eto H, Kato H, et al. In vivo manipulation of stem cells for adipose tissue repair/reconstruction. Regen Med. 2011; 6: 33-41. 
50. Moseley TA, Zhu M, Hedrick MH. Adipose-derived stem and progenitor cells as fillers in plastic and reconstructive surgery. Plastic and Reconstructive Surgery. 2006; 118: 121S-128S.

51. Lee SK, Kim DW, Dhong ES, et al. Facial Soft Tissue Augmentation using Autologous Fat Mixed with Stromal Vascular Fraction. Archivial Plastic Surgery. 2012; 39: 534-539.

52.Zhou BR, Zhang T, Bin Jameel AA, et al. The efficiency of conditioned media of adipose-derived stem cells combined with ablative carbon dioxide fractional resurfacing for atrophic acne scars and skin rejuvenation. J Cosmet Laser Her. 2016; 18: 138-148.

53. Meruane MA, Rojas M, Marcelain K. The use of adipose tissue-derived stem cells within a dermal substitute improves skin regeneration by increasing neoangiogenesis and collagen synthesis. Plast Reconstr Surg. 2012; 130(1): 53-63.

54. Salahat MA, LA Hadid. Autologous Adipose Stem Cells Use for Skin Regeneration and Treatment in Humans. J Biol Agr and Health. 2013; 3(1).

55. Mahajan PV, Subramanian S, Parab SC, et al. Regenerative Medicine Using Platelet Rich Plasma and Stem Cells in Atrophic Acne Scars: A Case Report. J Cosmo Trichol. 2017; 3: 2.

56. Vegiopoulos A, Müller-Decker K, Strzoda D, et al. Cyclooxygenase-2 controls energy homeostasis in mice by de novo recruitment of brown adipocytes. Science 2010; 328(5982): 1113-1114.
57. Ye J, Gao Z, Yin J, et al. Hypoxia is a potential risk factor for chronic inflammation and adiponectin reduction in adipose tissue of ob/ob and dietary obese mice. Am J Physiol Endocrinol Metab. 2007; 293: E1118-E1128.

58. Louwen F, Ritter A, Kreis NN, Yuan J. Insight into the development of obesity: functional alterations of adipose-derived mesenchymal stem cells. Obes Rev. 2018; 19(7): 888-904.

59. Cao Y. Adipose tissue angiogenesis as a therapeutic target for obesity and metabolic diseases. Nat Rev Drug Discov. 2010; 9(2): 107-15.

60. Cao Y. Angiogenesis as a therapeutic target for obesity and metabolic diseases. Chem Immunol Allergy. 2014; 99: 170-9.

61. Brakenhielm E, Cao Y. Angiogenesis in adipose tissue. Methods Mol Biol. 2008; 456: 65-81.

62. Cao Y. Angiogenesis modulates adipogenesis and obesity. J Clin Invest. 2007; 117(9): 2362-2368.

63. Kamba T, Tam BY, Hashizume H, et al. VEGF-dependent plasticity of fenestrated capillaries in the normal adult microvasculature. Am J Physiol Heart Circ Physiol. 2006; 290: H560-H576.

64. Sterodimas A, de Faria J, Nicaretta B, Pitanguy I. Tissue engineering with adipose-derived stem cells (ADSCs): current and future applications. J Plast Reconstr Aesthet Surg. 2010; 63(11): 1886-1892.

65. Robey P. "Mesenchymal stem cells": fact or fiction, and implications in their therapeutic use. F1000Research. 2017; 6(F1000 Faculty Rev): 524. 